\title{
Tensegrity-Inspired Polymer Nanocomposites
}

Ji Hoon Lee ${ }^{1}$ and Meisha L. Shofner ${ }^{1,2^{*}}$

${ }^{1}$ School of Materials Science and Engineering, Georgia Institute of Technology, Atlanta, GA 30332

${ }^{2}$ Renewable Bioproducts Institute, Georgia Institute of Technology, Atlanta, GA 30332

\begin{abstract}
Investigating the design space available in nanofilled polymers is expected to produce materials with unique structure-property relationships. In this work, the concept of tensegrity is used as inspiration for microstructural design. Tensegrity is an elegant and efficient structural design, relying upon interactions between elements, specifically elements in compression which are connected through a tensioned web. In this embodiment, the nanoparticles are considered the compressive elements, and the polymer matrix, when suitably processed, is considered the tensioned web. Nanocomposite materials containing polymer-decorated hydroxyapatite nanoparticles were used to evaluate the tensegrity-inspired approach. Nanocomposite systems with a semi-crystalline matrix (polyethylene oxide) and an amorphous matrix (polymethyl methacrylate) were prepared and characterized with compatible polymer-decorated nanoparticles. The results showed that the nanocomposite with a semi-crystalline matrix was more promising as a candidate for producing the tensegrity-inspired microstructure and that the concept could produce improved thermomechanical properties in the glassy temperature regime.
\end{abstract}

Keywords: Polymer Nanocomposite; Viscoelastic Properties; Tensegrity

*Corresponding Author. Telephone: (404) 385-7216, Fax: (404) 894-8780, Email: meisha.shofner@mse.gatech.edu 


\section{Introduction}

The processing-structure-property relationships of polymer nanocomposites have been widely studied in order to effectively leverage the inherent properties of nanoparticles as well as utilize the large amount of surface area provided by nanoscale inclusions to modify polymer conformation and mobility [1-7]. The results of these studies have produced materials with enhanced barrier properties [8-13], effective electrostatic dissipation [14-18], increased service temperatures through increases in the polymer matrix's glass transition temperature $\left(T_{g}\right)[19,20]$, improved mechanical properties [21-25], and in some instances improved mechanical performance where strength, modulus, and strain to failure are simultaneously improved [26, 27]. This wide range of value added properties can be produced in part because the library of components available for the design and construction of a polymer nanocomposite is impressively large. Polymers are chemically and structurally diverse. Chemical diversity can come from elemental composition along the backbone as well as in side groups. Structural diversity arises from many factors including degree of crystallinity, chain architecture, molecular weight, molecular weight distribution, and intermolecular bonding. In addition, the chemical composition of nanoparticles spans all three major materials classes, and the ability to surface modify nanoparticles provides yet another route to tailor the nanocomposite composition, function, and component interactions. Overall, the many possibilities for nanocomposite components provides a rich materials space for research.

Further attempts to harness the potential of polymer nanocomposites have used purposeful structuring of the components through processing. In some cases, this structuring has been accomplished with widely used polymer processing techniques such as fiber spinning to orient high aspect ratio, anisotropic nanoparticles [28-32]. Layer-by-layer strategies have also 
been used to incorporate large nanoparticle loadings and provide in-plane orientation of nanoparticles [33-38]. In other cases, nanocomposites containing only nanoparticles with grafted polymer chains on their surfaces have been produced, eliminating weak component interfaces $[39,40]$. In many of these cases, the structuring has led to improved properties that have not been realized in polymer nanocomposites containing randomly distributed and oriented nanoparticles. In the research contained in this paper, a different, purposeful structuring methodology is pursued based on the concept of tensegrity.

Tensegrity is a contraction of the phrase 'tension integrity' and describes a system where discontinuous compressed components are connected through a tensioned web. The term tensegrity was coined by Richard Buckminster Fuller [41] though the invention and development of tensegrity is shared by at least two other people: David Georges Emmerich and Kenneth Snelson [42]. While Fuller choose to describe the concept as "islands of compression inside an ocean of tension", Emmerich described tensegrity structures as "systemes autotendants" which translates roughly to self-tensioning systems in English, and Snelson titled his patent "continuous tension, discontinuous compression structures". The different descriptions have allowed some flexibility and controversy in classifying a structure as a tensegrity structure, but within Motro's extended definition [42], three basic features are needed for a structure to be considered tensegrity:

1. The structure contains two kinds of components: compressed elements and tensioned element(s).

2. The compressed elements are discontinuous and inside of the continuous tensioned elements.

3. The system possesses self-equilibrium. 
An easily-visualized example of a simple tensegrity system described by Motro is an inflated balloon [42]. In this system, the air inside the balloon acts as the compressed component and the balloon acts as the tensioned component. If adequate pressure is present inside of the balloon, the structure resists deformation when you press your fingertip on the surface. If you have applied enough force to deform the balloon, the original state of equilibrium will be restored when the load is removed. Several more complex examples exist in nature and biology which consider the arrangement of the compressed components within the tensile web. Perhaps the most well-known, and at times controversial, application of a tensegrity model is to mechanotransduction in cells $[43,44]$. Additionally, spider webs have been described similarly to tensegrity structures where the crystalline regions are the discontinuous compression elements connected by the amorphous material $[45,46]$. Intricate DNA-templated trusses have also been produced with a tensegrity design using specific interactions [47, 48]. Beyond natural systems and materials, the concept of tensegrity has been applied to the design of deployable structures $[49,50]$, and as a model to understand the properties of liquid crystalline elastomer networks [51] and embedded nanostructures [52]. Composite materials are also being considered as vehicles for tensegrity design owing to their inherent two (or more) phase structure, component property contrast, and mutable component arrangement at different length scales [53-55].

In this research, tensegrity principles were used as inspiration for the design of polymer nanocomposite microstructures in two-dimensional films with the motivation of improving mechanical properties of discontinuously reinforced nanocomposite materials. The concept of tensegrity was applied by considering the nanoparticles as the discontinuous compressed components and the surrounding matrix as the tensioned element. The concept of selfequilibrium was addressed through prestress in the matrix from drawing operations leading to the 
arrangement of the compressed components in the polymer matrix. Two nanocomposite systems were investigated to understand more fully how elements of polymer structure (amorphous and crystalline) contributed to the efficacy of the approach. Overall, the results suggested that the original structure of the matrix was an important consideration for implementing this tensegrityinspired design and that this methodology has the potential to produce polymer nanocomposites with improved stiffness in the glassy temperature regime.

\section{Experimental}

Two nanocomposite systems were prepared and characterized in this research. The first system contained polymer-decorated hydroxyapatite (HAp) nanoparticles and a poly(ethylene oxide) (PEO) matrix ( $\mathrm{M}_{v}=300,000 \mathrm{~g} / \mathrm{mol}$, Aldrich). The HAp nanoparticles were coated with a PEO- $b$-poly(methyacrylic acid) (PEO- $b$-PMAA) copolymer during synthesis, with the PEO block forming the outer layer [56]. The nanoparticles were needle-shaped with a length of $330 \pm$ $30 \mathrm{~nm}$ and a diameter of $55 \pm 5 \mathrm{~nm}$. The second system contained polymer-decorated HAp nanoparticles and a poly(methyl methacrylate) (PMMA) matrix $\left(\mathrm{M}_{w}=120,000 \mathrm{~g} / \mathrm{mol}\right.$, Aldrich). These HAp nanoparticles were coated with a PMMA- $b$-PMAA copolymer during synthesis, with the PMMA block forming the outer layer [57]. These nanoparticles were also needle-shaped and had a length of $311 \pm 36 \mathrm{~nm}$ and a diameter of $46 \pm 11 \mathrm{~nm}$. The two matrix polymers, PEO and PMMA, have semi-crystalline and amorphous morphologies, respectively.

Nanocomposites containing 15 wt.\% HAp and neat matrix samples for comparison were prepared in the PEO and PMMA systems using a multi-step processing protocol. The processing of the PEO nanocomposite began with dissolution of the matrix polymer in deionized water at 50 ${ }^{\circ} \mathrm{C}$ using magnetic stirring. The nanoparticles were sonicated for 10 minutes using a bath 
sonicator and then added to the polymer solution and magnetic stirring continued for 30 minutes. The nanocomposite suspension was then further processed using sonication with a cup-horn sonicator at a power of $80 \mathrm{~W}$ for 3 minutes and cast into a polystyrene Petri dish. The water was allowed to evaporate in the fume hood for 24 hours and then in a vacuum oven for four hours. Finally, the cast film was consolidated by compression molding at temperature of $80{ }^{\circ} \mathrm{C}$ and an applied force of five tons for 10 minutes. The sample was cooled to room temperature under pressure using water cooling. The nominal cooling rate applied was $15^{\circ} \mathrm{C} /$ minute. The resulting film had a thickness of approximately $0.1 \mathrm{~mm}$. Neat PEO samples were processed using the same protocol for comparison.

In order to arrange the HAp nanoparticles in the polymer matrix, the nanocomposite material and the neat PEO material were drawn along two different directions in sequential steps as shown in Figure 1. Film drawing was carried out at room temperature using an Instron 5566 testing frame and a TA Instruments Q800 dynamic mechanical analyzer (DMA). Room temperature is approximately $70{ }^{\circ} \mathrm{C}$ above the glass transition temperature $\left(T_{g}\right)$ for PEO. For the first drawing step, a film with dimensions of $25 \mathrm{~mm}$ x $30 \mathrm{~mm}$ (width $\mathrm{x}$ length) was prepared and drawn at a crosshead speed of $10 \mathrm{~mm} / \mathrm{min}$ up to $30 \%$ strain. For the second drawing step, the film was drawn in the perpendicular direction with a crosshead speed of $10 \mathrm{~mm} / \mathrm{min}$ up to $15 \%$ strain.

For the PMMA samples, the processing protocol was similarly structured but with a different solvent and different temperatures dictated by differences in matrix-solvent compatibility and differences in matrix thermal transition temperatures (melting and glass transition, as applicable). First a polymer solution was prepared by dissolving PMMA in tetrahydrofuran (THF, EMD Chemicals) at room temperature using magnetic stirring. The 
nanoparticle suspension was sonicated for 10 minutes using a bath sonicator and then added to the polymer solution. The nanocomposite suspension was mixed for an additional 30 minutes using magnetic stirring and then sonicated using a cup horn sonicator at a power of $80 \mathrm{~W}$ for 15 minutes. The nanocomposite suspension was then cast into a PTFE Petri dish. The solvent was allowed to evaporate in a fume hood for 24 hours and then further dried in a vacuum oven for four hours at $50{ }^{\circ} \mathrm{C}$. The film was then further consolidated using compression molding at a temperature of $180{ }^{\circ} \mathrm{C}$ and applied force of five tons for 10 minutes. The sample was cooled under pressure to room temperature. Prior to characterization, the film sample was annealed under vacuum for $24 \mathrm{hr}$ at $145^{\circ} \mathrm{C}$ and then slowly cooled to room temperature. The resulting film had thickness of $0.1 \mathrm{~mm}$. A neat PMMA sample was processed using the same processing conditions for comparison. The drawn films were prepared using the procedure as the PEO nanocomposite system except for the drawing temperature (in this system, the temperature was $\left.120^{\circ} \mathrm{C}\right)$.
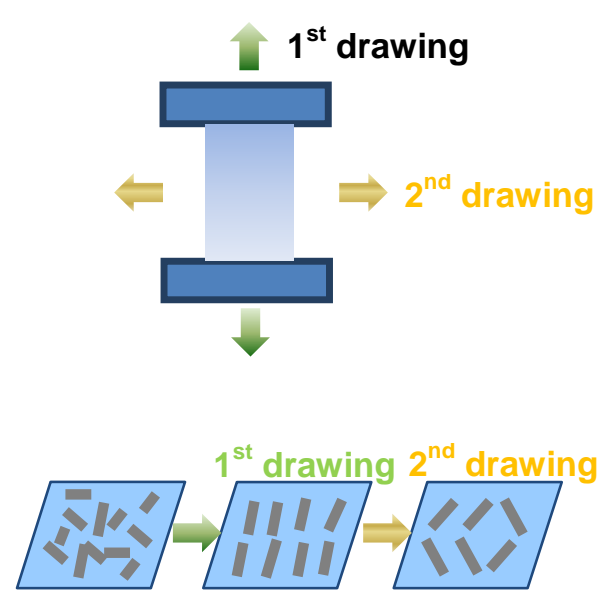
Figure 1. Schematic of drawing steps to produce the tensegrity-inspired microstructure.

For both systems and neat polymers, three types of samples were characterized. The first type of sample is described as isotropic, and these samples are the films produced after the compression molding step. These results for the PEO material were published in a separate publication along with results for HAp/PEO nanocomposites with a range of HAp loadings [58]. The characterization data for the $15 \mathrm{wt} \%$ isotropic samples are included here to provide reference data for the drawn samples. The second type of sample is described as uniaxial, and these samples are the films produced after the first drawing step. The third type of sample is described as biaxial, and these are the films produced after the second drawing step. The biaxial structure is the tensegrity-inspired structure. The characterization protocol employed to understand the structure and properties of these three sample types is described below.

The dispersion and distribution of the nanoparticles in the matrices as a function of processing steps was observed using scanning electron microscopy (SEM). Prior to imaging, the surfaces were prepared using a FEI Nova Nanolab 200 focused ion beam (FIB)/SEM. The nanocomposite samples were coated with gold, and then, a focused $\mathrm{Ga}^{+}$ion beam implantation was performed with a beam current of $0.1 \mathrm{nA}$ for the HAp/PEO nanocomposites and $0.3 \mathrm{nA}$ for the HAp/PMMA nanocomposites. The milled surfaces were imaged using SEM.

The average orientation of the nanoparticles as a function of processing steps was calculated using X-ray diffraction data obtained from azimuthal scans of the (300) peak for HAp located at $2 \theta=32.9^{\circ}$. For the HAp/PEO nanocomposites, azimuthal scans were performed using a X'Pert PRO Alpha-1 XRD with $\mathrm{Cu}-\mathrm{K} \alpha$ radiation $\left(\lambda=1.54 \AA \mathrm{A}^{2}\right.$. Scattering intensity data were collected at azimuthal angles from $\beta=0^{\circ}$ to $360^{\circ}$ with a step size $0.05^{\circ}$ and time per step of 10 
second. For the HAp/PMMA nanocomposites, azimuthal scans were conducted on a Rigaku RAXIS IV equipped with an image plate. The $\mathrm{Cu}-\mathrm{K} \alpha$ radiation $(\lambda=1.54 \AA)$ monochromatized by a confocal optics system was used and the diffraction patterns were collected at azimuthal angles from $\beta=90^{\circ}$ to $360^{\circ}$. The sample setup for XRD measurement is shown in Figure 2 .

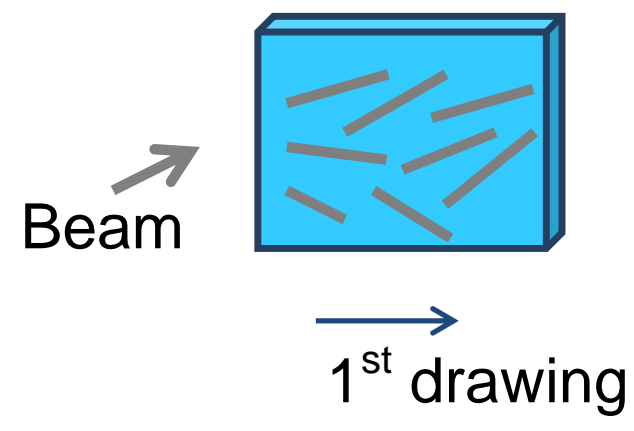

Figure 2. Schematic of experiment set-up for x-ray diffraction measurements.

The melting and crystallization temperatures as well as the matrix crystallinity for the neat PEO and the PEO nanocomposites were measured using a TA Instruments Q200 differential scanning calorimeter (DSC). The measurements were conducted using a lower bound temperature of $-70{ }^{\circ} \mathrm{C}$, an upper bound temperature of $100{ }^{\circ} \mathrm{C}$, and a heating and cooling rate of $10{ }^{\circ} \mathrm{C} / \mathrm{min}$. The melting and crystallization temperatures were reported as the heat flow peak maxima, and the crystallinity, $X_{c}$, of the polymer was calculated from the following equation.

$$
X_{\mathrm{c}}=\Delta H_{\mathrm{f}} /\left(w \Delta H_{\mathrm{f}}^{\mathrm{o}}\right)
$$

where $w$ is the weight fraction of PEO and $\Delta H_{\mathrm{f}}^{\mathrm{o}}$ is the heat of fusion of $100 \%$ crystalline PEO (205 J/g) [59]. The heat of fusion $\left(\Delta H_{\mathrm{f}}\right)$ for the composite was obtained from integrating the melting peak of the heating cycle. The thermal transitions and the percent crystallinity were 
reported as the average value obtained from two separate DSC experiments with different samples.

Thermomechanical properties were measured using a Mettler Toledo DMA861 ${ }^{\mathrm{e}}$ DMA. All tests were performed in shear using a double shear sandwich fixture with a stacked film sample. The stacked films were composed of two sample films, and each film was separated by an aluminum disk. The stacked films preparation was based on a technical note from the instrument manufacturer [60]. The tests for the PEO-based systems were performed over a temperature range of $-75^{\circ} \mathrm{C}$ to $25^{\circ} \mathrm{C}$, and the tests for the PMMA-based systems were carried out over a temperature range of $30{ }^{\circ} \mathrm{C}$ to $150{ }^{\circ} \mathrm{C}$. For testing with the uniaxial and biaxial samples, the samples were oriented so that the deformation was coincident with the first drawing direction. All tests used a heating rate of $2{ }^{\circ} \mathrm{C} /$ minute and a frequency of $1 \mathrm{~Hz}$. All measurements were carried out in the linear viscoelastic region with limiting force and displacement amplitude conditions. The average data were reported from two separate DMA tests using different samples of the same composition. The spread in the experimental values obtained was indicated with error bars.

\section{Results and Discussion}

To prepare HAp/PEO nanocomposites with different microstructures, the isotropic samples were drawn in two separate, sequential steps as described in the Experimental section and shown in Figure 1. Before drawing the samples, the HAp nanoparticle loading was chosen based on characterization data for isotropic HAp/PEO nanocomposites obtained previously [58]. Specifically, a particle loading of $15 \mathrm{wt} \%$ in this system showed predominately solid-like behavior in the melt and reduced matrix crystallinity, suggesting that the particles and matrix 
were coupled continuously through the sample and appreciably interacting. For the HAp/PMMA nanocomposite system, the same nanoparticle loading was used to compare with the HAp/PEO nanocomposite system.

Figure 3 shows FIB-SEM images of milled nanocomposite surfaces for the isotropic, uniaxial, and biaxial samples. The images show that the HAp nanoparticles were reasonably well-dispersed in the polymer matrix. For the isotropic samples, the images suggested that the HAp nanoparticles had no preferential orientation, indicating randomly dispersed particle morphology. However, preferentially oriented (aligned) particles could be observed in the uniaxial samples. As expected, the biaxial samples possessed a lower degree of nanoparticle alignment. However, it was difficult to determine objectively the particle arrangement from SEM images, so the alignment of HAp nanoparticles in the polymer matrix was further characterized using X-ray diffraction.

Azimuthal scans were performed on both nanocomposite systems using a two theta angle of $32.9^{\circ}$, corresponding to the (300) peak of HAp. Herman's orientation function, $f$, was calculated to quantify the average orientation of the nanoparticles using these data [61]. The equation used to calculate $f$ is shown below:

$$
f=\frac{3<\cos ^{2} \theta>-1}{2}
$$

In this expression, $\theta$ was the average angle between the c-axis of HAp and the first film drawing direction. 


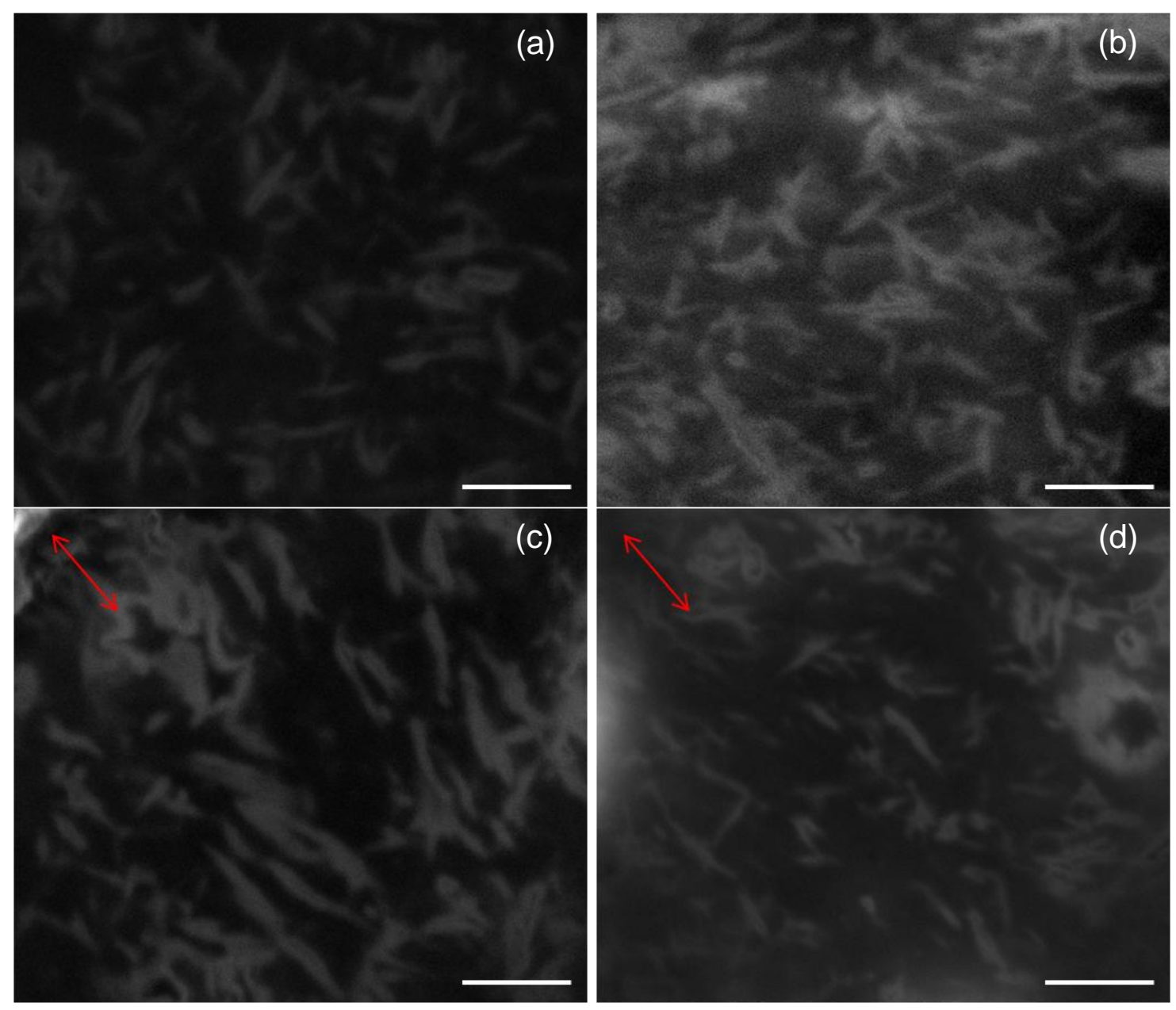



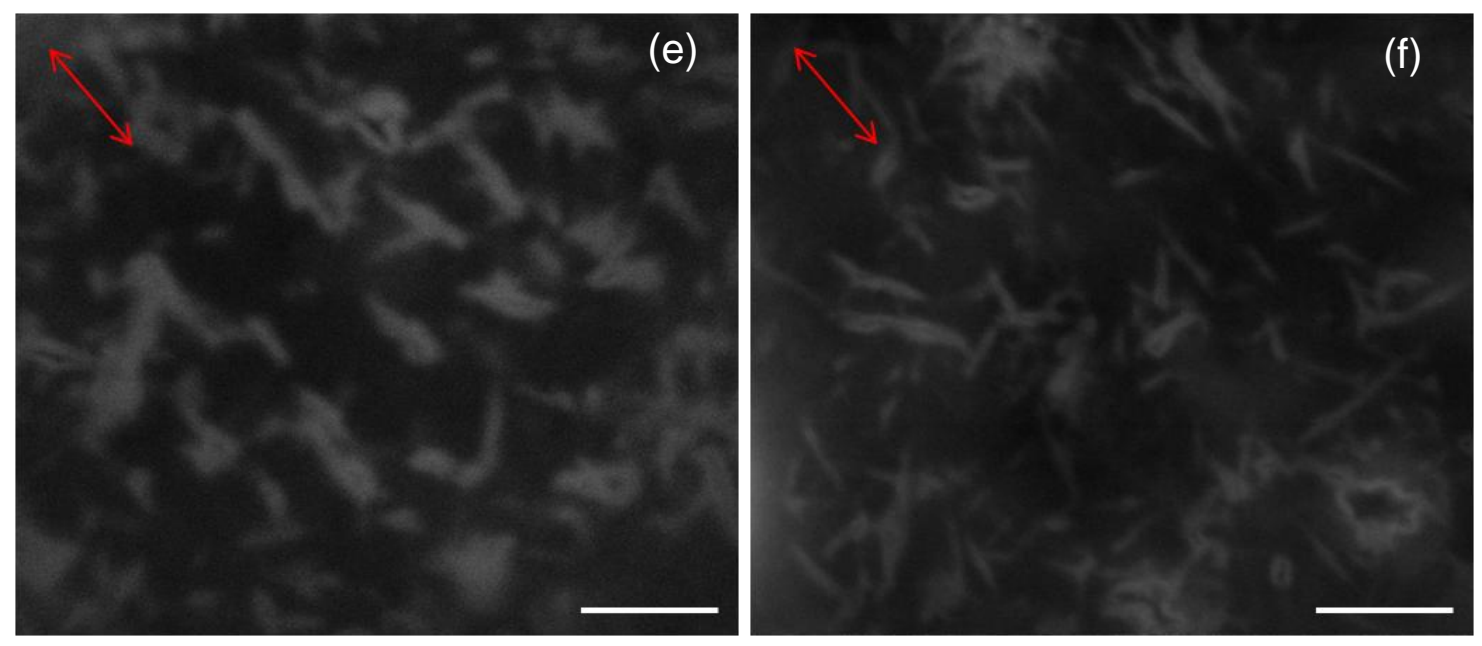

Figure 3. SEM micrographs. Isotropic HAp/PEO (a), isotropic HAp/PMMA (b), uniaxial HAp/PEO (c), uniaxial HAp/PMMA (d), biaxial HAp/PEO (e), biaxial HAp/PMMA (f). The scale bar represents $300 \mathrm{~nm}$. The arrows indicate the first drawing direction.

Figure 4 shows the results of the azimuthal scan of (300) diffraction plane for HAp/PEO nanocomposites. For the isotropic composite sample, no diffraction peak was observed, indicating that the HAp nanoparticles had no preferential orientation in the matrix. After both drawing processes, distinct peaks were seen in the azimuthal scans at $90^{\circ}$ and $270^{\circ}$, indicating that the drawing steps produced some degree of nanoparticle alignment with respect to the first drawing direction. The values of $f$ and the peak's full width at half maximum intensity (FWHM) for the HAp/PEO nanocomposites following the first and second drawing operations were 0.66 (FWHM: $27^{\circ}$ ) and 0.55 (FWHM: $34^{\circ}$ ), respectively. For the HAp/PMMA nanocomposite, the results of the azimuthal scan are shown in Figure 5. Qualitatively similar results were seen for this nanocomposite though the amount of preferential orientation achieved was lower than that in the HAp/PEO nanocomposite. The values of $f$ were 0.15 (FWHM: $47^{\circ}$ ) and $0.1\left(\mathrm{FWHM}: 50^{\circ}\right.$ ) for the first and second drawing, respectively. Based on the values of $f$ calculated from the data and the FIB-SEM images, the nanoparticle orientation was greater following the first drawing 
step and reduced following the second drawing step, as expected. Differences in the degree of orientation attained between the two nanocomposites were attributed to the matrix structure. This effect was studied further with thermal analysis experiments.

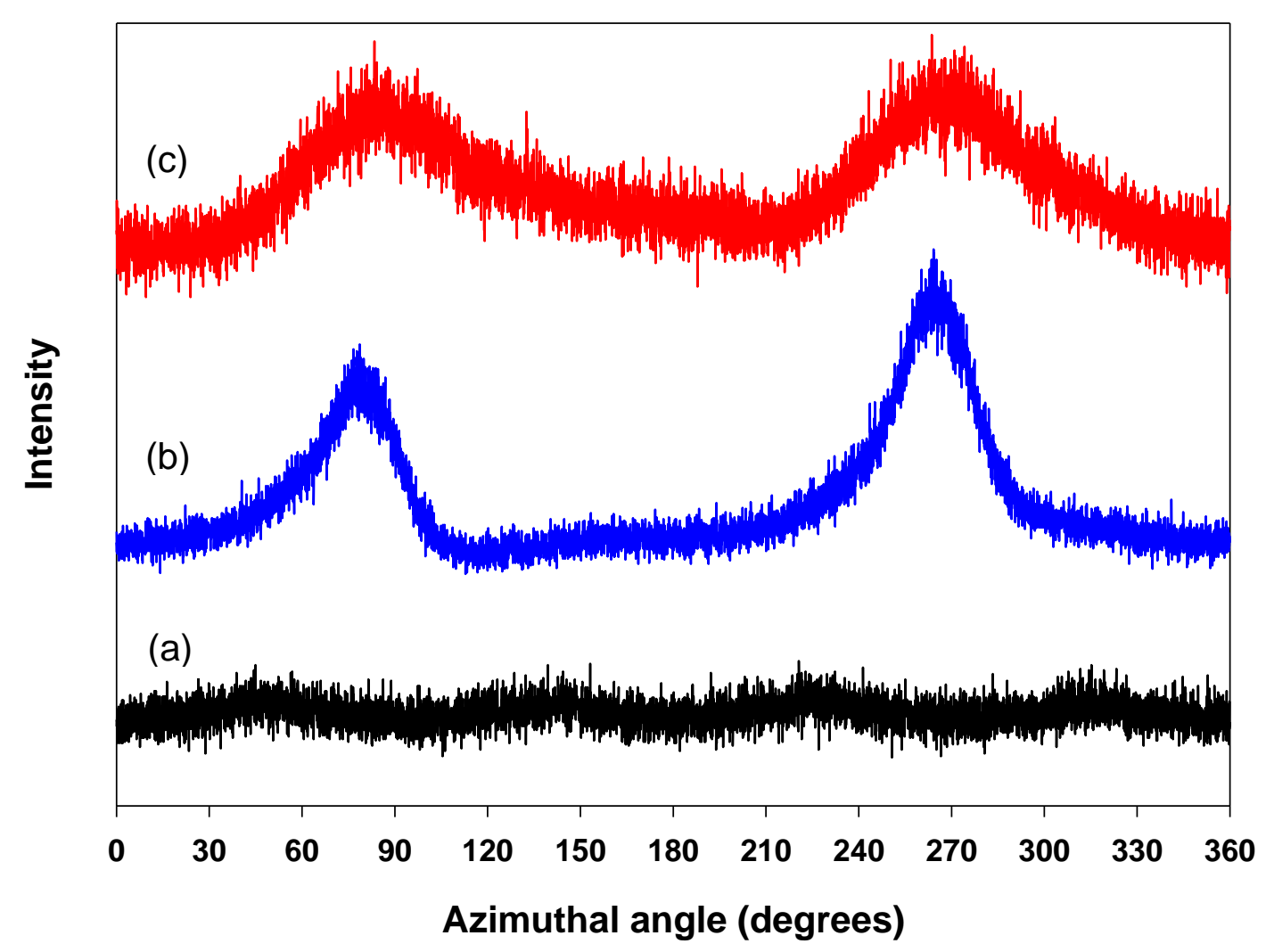

Figure 4. Azimuthal scan of (300) diffraction from isotropic (a), uniaxial (b), and biaxial (c) HAp/PEO composites. 


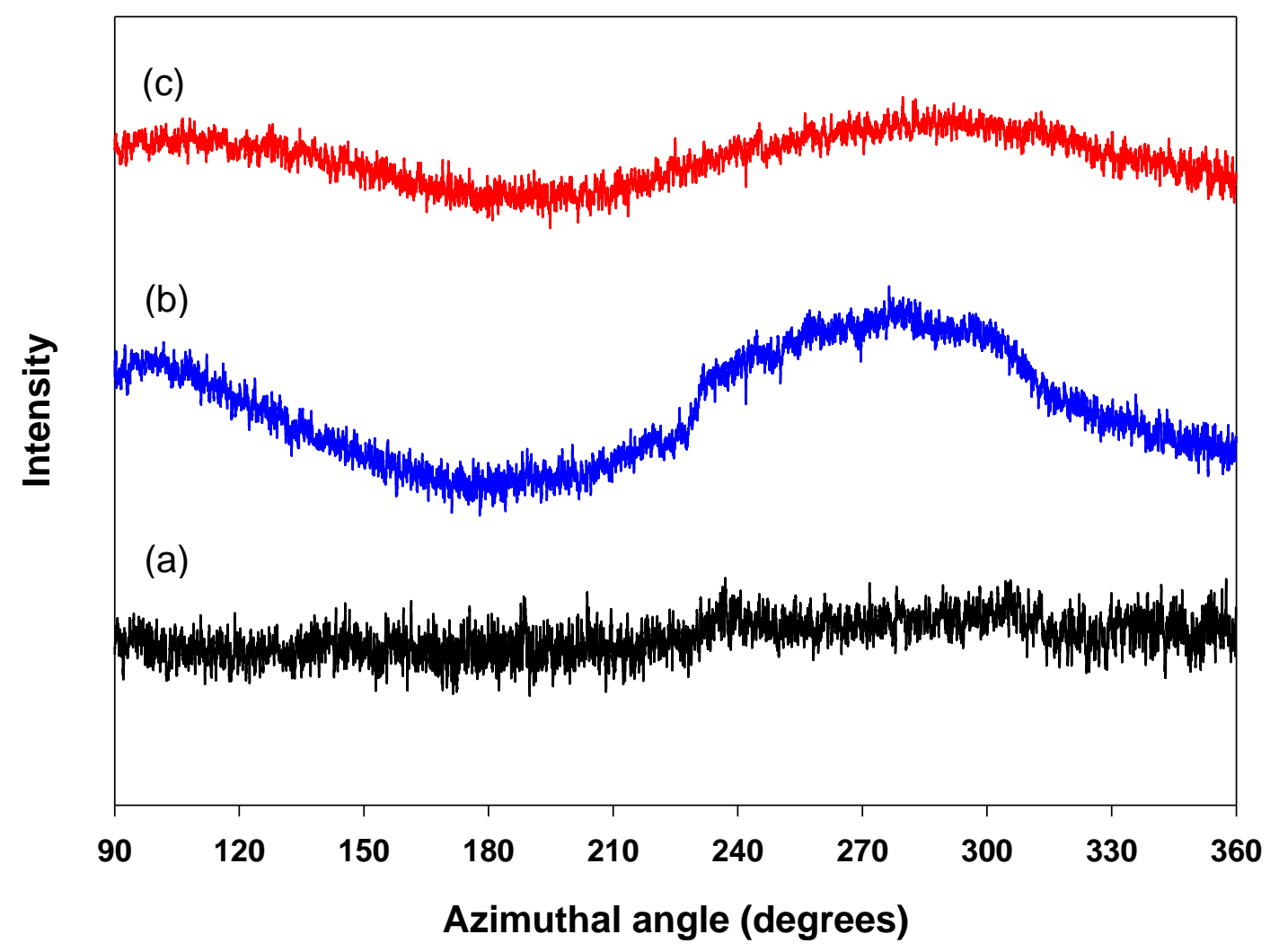

Figure 5. Azimuthal scan of (300) diffraction from isotropic (a), uniaxial (b), and biaxial (c) HAp/PMMA composites.

Thermal transitions and crystallization behaviors for isotropic and anisotropic samples of neat PEO and the HAp/PEO nanocomposite were measured using DSC, and the results are shown in Table 1. The drawing process did not significantly influence the peak crystallization and melting temperatures measured during the first and second cycle for any of the samples. Any changes were within approximately $2{ }^{\circ} \mathrm{C}$. For the neat PEO, the polymer crystallinity measured during the first heating cycle was slightly increased with the drawing steps. Such a change was consistent with reported behavior for drawn polymer films where drawing promotes stress- 
induced crystallization $[62,63]$. However, a change in the crystallinity of only $2 \%$ was observed which was not a significant enough change to conclude definitively that stress-induced crystallinity occurred. For the HAp nanocomposite, the polymer crystallinity measured during the first heating cycle was increased after the first drawing process by a larger amount, approximately $7 \%$. Negligible change in the polymer crystallinity with respect to the first drawing step was observed after the second drawing step. For the HAp nanocomposite, stressinduced crystallization was likely the mechanism responsible for the increase in polymer crystallinity after drawing. The isotropic HAp nanocomposite had a lower amount of crystallinity than the neat PEO, providing a larger available amorphous fraction, which could crystallize during drawing. Additionally, the neat PEO and HAp/PEO had approximately the same amount of crystallinity following the drawing steps. As expected, any effects of stress-induced crystallization were erased after melting, and data obtained during the second heating cycle for isotropic and anisotropic samples had similar values.

Table 1. The thermal transition temperatures and crystallinity of isotropic and anisotropic samples.

\begin{tabular}{|l|c|c|c|c|c|c|}
\hline & \multicolumn{2}{|c|}{ Crystallinity $(\%)$} & \multicolumn{2}{c|}{$\mathrm{T}_{\mathrm{c}}\left({ }^{\circ} \mathrm{C}\right)$} & \multicolumn{2}{c|}{$\mathrm{T}_{\mathrm{m}}\left({ }^{\circ} \mathrm{C}\right)$} \\
\hline & $\begin{array}{c}\mathbf{1}^{\text {st }} \\
\text { Heating }\end{array}$ & $\begin{array}{c}\mathbf{2}^{\text {nd }} \\
\text { Heating }\end{array}$ & $\begin{array}{c}\mathbf{1}^{\text {st }} \\
\text { Heating }\end{array}$ & $\begin{array}{c}\mathbf{2}^{\text {nd }} \\
\text { Heating }\end{array}$ & $\begin{array}{c}1^{\text {st }} \\
\text { Heating }\end{array}$ & $\begin{array}{c}2^{\text {nd }} \\
\text { Heating }\end{array}$ \\
\hline Neat PEO, isotropic & $70(0.6)$ & $72(0.5)$ & $47(0.3)$ & $47(0.4)$ & $66(0.3)$ & $67(0.1)$ \\
\hline Neat PEO, uniaxial & $73(1.7)$ & $72(1.3)$ & $45(1.1)$ & $45(1.0)$ & $65(1.3)$ & $65(0.4)$ \\
\hline Neat PEO, biaxial & $73(1.5)$ & $71(1.3)$ & $46(0.5)$ & $46(0.5)$ & $65(0.1)$ & $65(0.3)$ \\
\hline 15wt\% HAp, isotropic & $64(0.3)$ & $64(0.4)$ & $44(0.4)$ & $44(0.7)$ & $64(0.4)$ & $65(0.4)$ \\
\hline 15wt\% HAp, uniaxial & $71(2.0)$ & $65(3.3)$ & $46(0.1)$ & $46(0.0)$ & $65(0.0)$ & $64(0.1)$ \\
\hline 15wt\% HAp, biaxial & $72(2.1)$ & $64(2.3)$ & $47(0.2)$ & $46(0.3)$ & $65(0.2)$ & $64(0.3)$ \\
\hline
\end{tabular}


In order to evaluate the role of component interactions and matrix structure on the construction and properties of a tensegrity-inspired microstructure, the thermomechanical properties of the samples were measured. The storage modulus $\left(G^{\prime}\right)$ and loss modulus $\left(G^{\prime \prime}\right)$ of the neat PEO and HAp nanocomposite samples as a function of temperature are shown in Figure 6. The data collected allowed for an understanding of the effects of adding HAp particles to PEO (comparing the results for the neat polymer to the nanocomposite in all three sample types) and the effects of microstructure (comparing the results for all three sample types of the nanocomposite). The $G^{\prime}$ data were used to understand the reinforcement provided by particle addition and arrangement, and both the $G^{\prime}$ and $G^{\prime \prime}$ data were used to understand differences in matrix structure caused by the addition of particles and the drawing steps.

Comparing the neat PEO samples to the nanocomposite samples, the addition of HAp provided reinforcement to the PEO matrix as shown by the increase in $G^{\prime}$ values across the temperature range measured. Table 2 contains $G^{\prime}$ data for a temperature below $T_{g}$, a temperature near the loss modulus peak for neat isotropic PEO, and a temperature above $T_{g}$. When comparing the neat PEO and nanocomposite samples that experienced the same processing steps (i.e. uniaxial neat PEO to uniaxial HAp/PEO) the curves for each sample set with the same processing steps had similar shapes, though were different in magnitude. The drawing steps generally increased the value of $G^{\prime}$, and the amount of reinforcement with drawing was more pronounced at temperatures greater than $T_{g}$ for both the neat $\mathrm{PEO}$ and the HAp/PEO nanocomposite. For the neat PEO, the increased values of $G^{\prime}$ were due to the structural changes in the polymer produced by the drawing steps, i.e. increased polymer chain alignment and/or slightly increased polymer crystallinity. These difference in polymer structure with drawing were also apparent in the $G^{\prime}$ and $G^{\prime \prime}$ data trends in the vicinity of $T_{g}$. The decrease in $G^{\prime}$ values 
associated with $T_{g}$ was smaller in the drawn samples, indicating that a smaller population of polymer chains became mobile at $T_{g}$. Additionally, $G^{\prime \prime}$ data just above $T_{g}$ for the drawn PEO samples showed a plateau instead of the peak seen with the isotropic PEO, supporting the trend seen with $G^{\prime}$ data. The value of $T_{g}$ was also changed with drawing. Using the peak maxima of $G^{\prime \prime}$ to assign $T_{g}$, the value for isotropic neat PEO was approximately $-47{ }^{\circ} \mathrm{C}$. For the drawn samples, $T_{g}$ was increased, and the value was approximately $-41^{\circ} \mathrm{C} \pm 1{ }^{\circ} \mathrm{C}$. The increased value of $G^{\prime}$ in the nanocomposite samples could be attributed to structural changes in the matrix as well as the different nanoparticle arrangements. When compared to the neat PEO samples, the same trends in $G^{\prime \prime}$ and in the value of $T_{g}$ were also observed for the nanocomposite samples, suggesting that the drawing reduced the mobility of the amorphous polymer chains in a similar way.

In order to compare the reinforcement efficacies more easily, relative storage modulus $\left(G_{r}{ }^{\prime}\right)$ was calculated as shown in Figure 7. $G_{r}{ }^{\prime}$ was calculated by dividing the $G^{\prime}$ values for each sample by the corresponding $G^{\prime}$ values for the isotropic neat PEO. These $G_{r}{ }^{\prime}$ values were compared to a theoretical prediction for reinforcement using a model proposed by Guth [64] and shown below:

$$
\frac{G_{c}^{\prime}}{G_{m}^{\prime}}=G_{r}^{\prime}=1+0.67 f \cdot c+1.62 f^{2} \cdot c^{2}
$$

In this model, $G_{c}{ }^{\prime}$ and $G_{m}{ }^{\prime}$ are the storage modulus values for the composite and matrix, respectively; $f$ is the aspect ratio of the particles; and $c$ is the volume concentration of particles. For this system, the particle aspect ratio was 6 , and the particle volume concentration was approximately 0.057 . The volume concentration was calculated from the particle weight loading assuming that the HAp density was $3.1 \mathrm{~g} / \mathrm{cm}^{3}$, the PEO density was $1.21 \mathrm{~g} / \mathrm{cm}^{3}$, the copolymer density was $1.18 \mathrm{~g} / \mathrm{cm}^{3}$, and the copolymer surface coating on the particle contributed $11.1 \%$ of 
the particle mass [56]. With these values for $f$ and $c$, the theoretical value of $G_{r}{ }^{\prime}$ was 1.41 . This value was similar to the experimental values of $G_{r}{ }^{\prime}$ obtained for the isotropic and uniaxial PEO nanocomposite at $-70^{\circ} \mathrm{C}$, suggesting that an additional reinforcement mechanism was present in the biaxial nanocomposite. The reinforcement character of the samples showed a temperature dependence with higher levels of reinforcement generally observed at higher temperatures. Appreciable differences in reinforcement character with processing steps were seen in the neat PEO samples at temperatures above $T_{g}$, with the sample subjected to two drawing steps showing a higher level of reinforcement. Since the crystallinity was similar for these two samples, this result suggested that there was beneficial structuring of the amorphous polymer in the neat biaxial sample. 


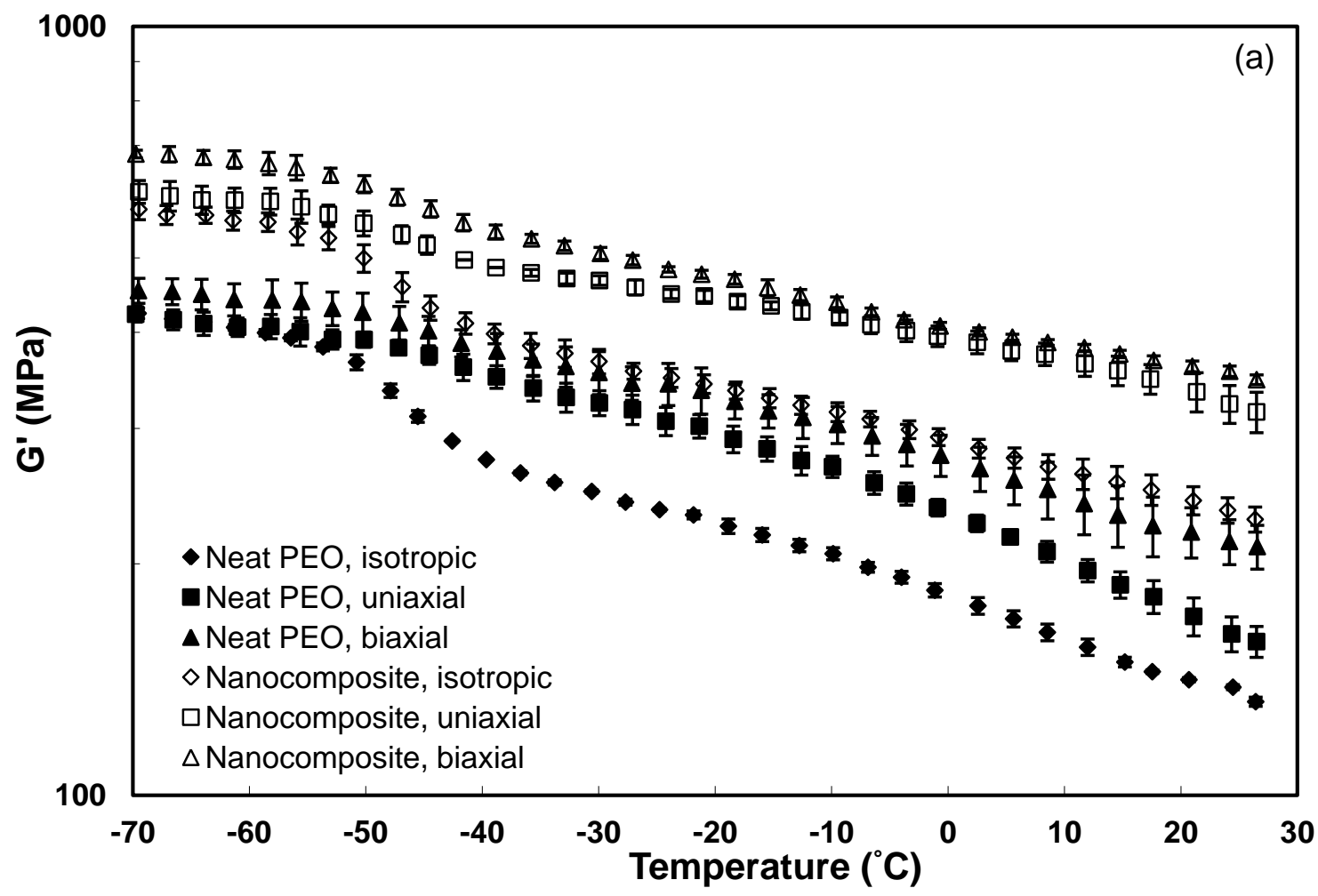




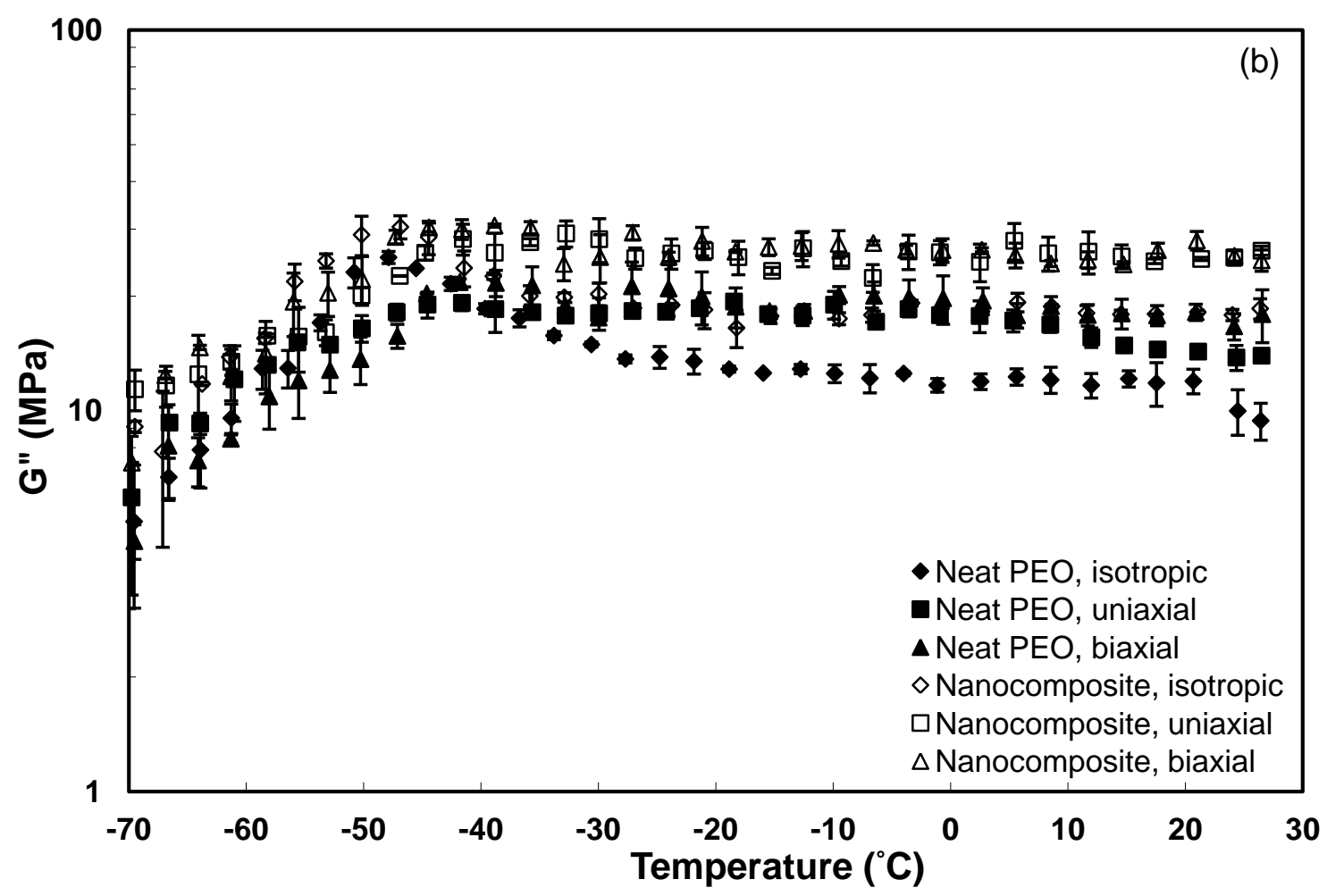

Figure 6. Storage modulus (a) and loss modulus (b) for PEO-based samples.

Table 2. Values of $G^{\prime}$ for the PEO-based materials at selected temperatures.

\begin{tabular}{|l|c|c|c|}
\hline Sample & $G^{\prime}$ at $\sim-70^{\circ} \mathrm{C}$ & $G^{\prime}$ at $\sim-47^{\circ} \mathrm{C}$ & $G^{\prime}$ at $\sim 21^{\circ} \mathrm{C}$ \\
\hline Neat PEO, isotropic & $423 \pm 6$ & $336 \pm 7$ & $141 \pm 1$ \\
\hline Neat PEO, uniaxial & $422 \pm 10$ & $382 \pm 8$ & $171 \pm 10$ \\
\hline Neat PEO, biaxial & $453 \pm 17$ & $412 \pm 21$ & $220 \pm 17$ \\
\hline Nanocomposite, isotropic & $578 \pm 18$ & $458 \pm 20$ & $242 \pm 10$ \\
\hline Nanocomposite, uniaxial & $609 \pm 21$ & $536 \pm 14$ & $335 \pm 20$ \\
\hline Nanocomposite, biaxial & $682 \pm 8$ & $599 \pm 14$ & $361 \pm 6$ \\
\hline
\end{tabular}




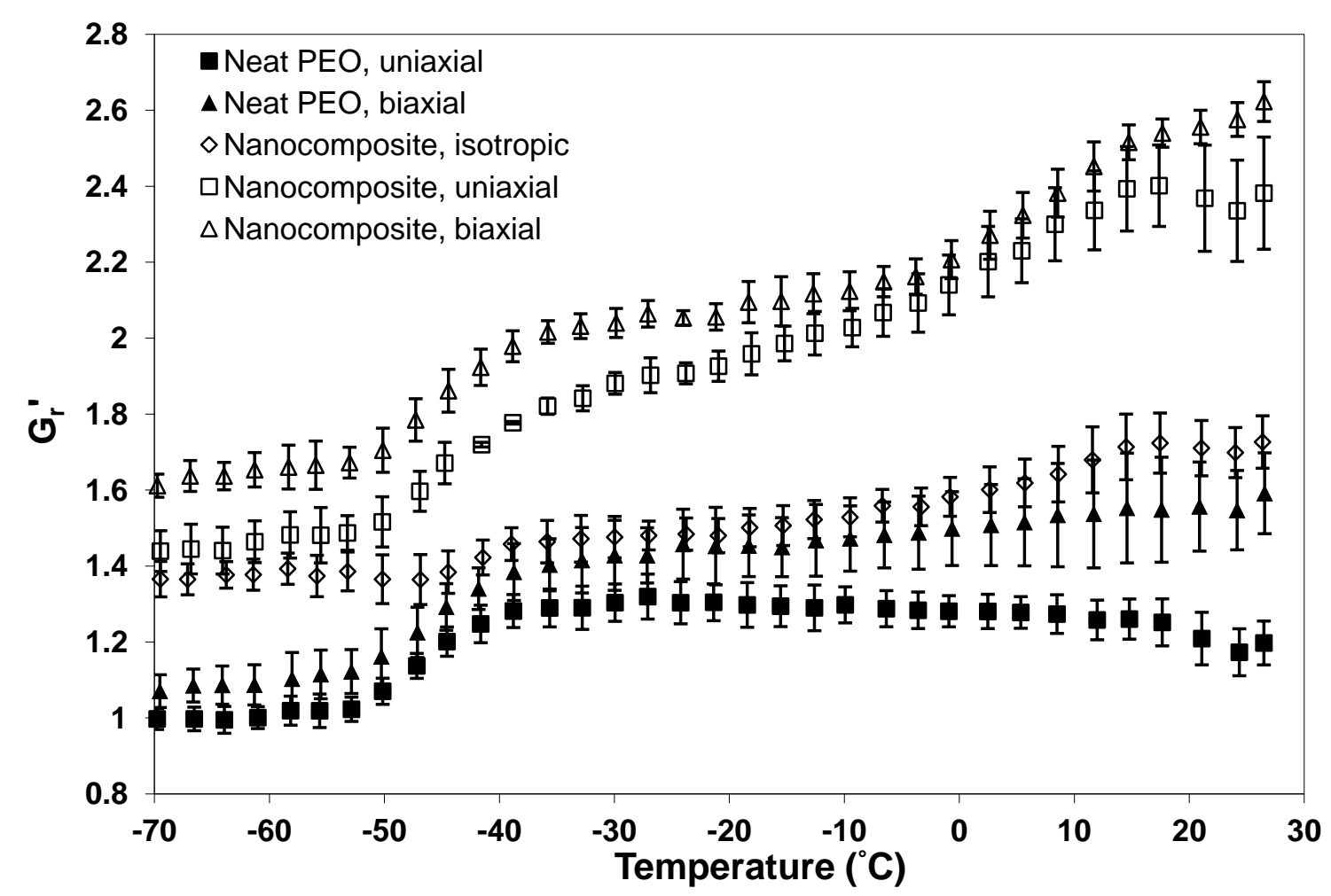

Figure 7. Relative storage modulus data for the PEO-based samples. Data are normalized with respect to the storage modulus data for the isotropic neat PEO sample.

The nanocomposite samples showed somewhat different trends, indicating that the interactions between the nanoparticles, the nanoparticle arrangements, and the matrix structuring were not strictly additive. When considering the three types of nanocomposite samples, the isotropic nanocomposite sample showed the lowest amount of reinforcement and the lowest level of temperature dependence for the reinforcement. These results provided insight into the contribution of nanoparticles only. Since there was some temperature dependence to the data for the isotropic nanocomposite, it was inferred that the polymer-decorated nanoparticles provided some hinderance to polymer mobility through interfacial interactions. Considering the additional effects of the drawing steps, the biaxial nanocomposite sample showed a higher level of reinforcement than the corresponding uniaxial sample at temperatures up to approximately -20 
${ }^{\circ} \mathrm{C}$. This temperature corresponded with the high temperature boundary of the $G^{\prime \prime}$ peak for the neat PEO, suggesting that the differences in the reinforcement character between these two samples was linked to the structuring of the amorphous polymer. In both drawn nanocomposite samples, the amount of matrix crystallinity was approximately equal; therefore, amorphous tie chains in the sample would accommodate deformation imposed by the second drawing step. These chains would provide connectivity between rigid elements such as polymer crystallites and/or the nanoparticles through different types of interactions. At temperatures greater than -20 ${ }^{\circ} \mathrm{C}$, the differences between the uniaxial and biaxial nanocomposite samples were more difficult to discern since the error bars for these data sets overlapped, suggesting that nanoparticlepolymer interactions were weakened at higher temperatures even if interactions between amorphous polymer chains and polymer crystallites were not.

Examining the companion samples produced with the amorphous polymer matrix, PMMA, allowed for a qualitative understanding of the importance of polymer structure in the tensegrity-inspired design. Figure 8 shows the $G^{\prime}$ and $G^{\prime \prime}$ data for the neat PMMA and HAp nanocomposite samples as a function of temperature. Table 3 contains $G^{\prime}$ data for a temperature below $T_{g}$, a temperature near the loss modulus peak for neat isotropic PMMA, and a temperature above $T_{g}$. Comparing with the PEO system results, the drawing process did not significantly influence the value of $G^{\prime}$ for the PMMA-based samples. All of the neat samples had similar $G^{\prime}$ values, and all of the nanocomposite samples had similar $G^{\prime}$ values. With respect to the neat samples, the nanocomposites had larger $G^{\prime}$ and $G^{\prime \prime}$ values. One notable change was observed for the uniaxial nanocomposite sample. The glass transition appeared broader on the high temperature side of the transition. This effect was seen in the change of the shape of the $G^{\prime}$ curve above $120^{\circ} \mathrm{C}$ and in the broadening of the $G^{\prime \prime}$ peak in this same temperature range. However, the 
data for the biaxial nanocomposite sample were more similar to the isotropic nanocomposite. This result suggested that any alignment/restriction of polymer chains produced by the first drawing step was largely negated by the second drawing step, unlike the PEO-based nanocomposite samples. Additionally, the $G_{r}^{\prime}$ data, shown in Figure 9, further illustrated the limited property differences observed at temperatures removed from $T_{g}$. The Guth model described above was used as a theoretical comparison to the experimental $G_{r}^{\prime}$ values for the PMMA-based nanocomposites as well. For this nanocomposite system, a particle aspect ratio of 6 and a particle volume concentration of 0.055 were used, resulting in a theoretical value for $G_{r}^{\prime}$ of 1.40. The volume concentration in the PMMA-based nanocomposites was slightly lower than that in the PEO-based nanocomposites because the density of the matrix was lower $\left(1.18 \mathrm{~g} / \mathrm{cm}^{3}\right)$ and the copolymer coverage was higher (11.8\% [57]). The predicted value was similar to the experimental value of approximately 1.5 at $35^{\circ} \mathrm{C}$ for the three PMMA-based nanocomposites.

Overall, the property trends observed for the two different nanocomposite system provided guidance on the efficacy of this microstructural design approach. With regard to structuring of the system, a higher degree of nanoparticle orientation was obtained for the PEO system, as shown by the azimuthal x-ray data. Qualitatively, similar trends in nanoparticle ordering were achieved with the PMMA matrix, but the degree of ordering was less. This result suggested that the polymer crystal structure provided a beneficial constraint and helped to orient the nanoparticles, allowing the formation of the tensegrity-inspired structure through pre-stress in the matrix structure and arrangement of the nanoparticles. The amorphous PMMA matrix could accommodate the drawing steps with a lesser degree of permanent structural change, not forming the tensioned network needed for tensegrity. 

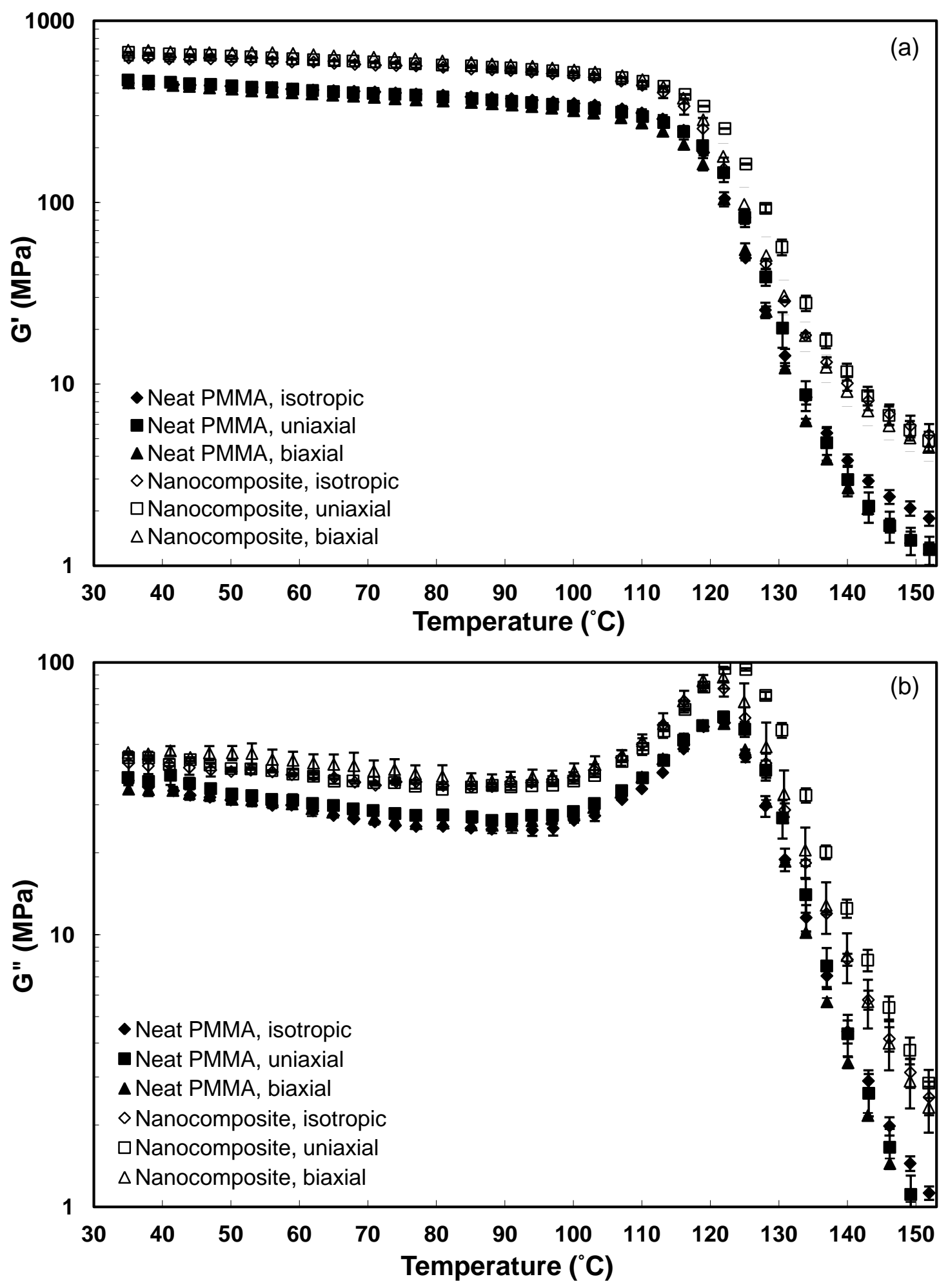

Figure 8. Storage modulus (a) and loss modulus (b) for PMMA-based samples. 
Table 3. Values of $G^{\prime}$ for the PMMA-based materials at selected temperatures.

\begin{tabular}{|l|c|c|c|}
\hline Sample & $G^{\prime}$ at $\sim 35^{\circ} \mathrm{C}$ & $G^{\prime}$ at $\sim 122{ }^{\circ} \mathrm{C}$ & $G^{\prime}$ at $\sim 149{ }^{\circ} \mathrm{C}$ \\
\hline Neat PMMA, isotropic & $454 \pm 17$ & $105 \pm 2$ & $2.1 \pm 0.2$ \\
\hline Neat PMMA, uniaxial & $472 \pm 5$ & $146 \pm 7$ & $1.4 \pm 0.2$ \\
\hline Neat PMMA, biaxial & $455 \pm 24$ & $104 \pm 9$ & $1.4 \pm 0.1$ \\
\hline Nanocomposite, isotropic & $624 \pm 20$ & $153 \pm 24$ & $5.9 \pm 0.8$ \\
\hline Nanocomposite, uniaxial & $671 \pm 4$ & $255 \pm 1$ & $5.6 \pm 0.7$ \\
\hline Nanocomposite, biaxial & $688 \pm 9$ & $179 \pm 33$ & $5.0 \pm 0.8$ \\
\hline
\end{tabular}

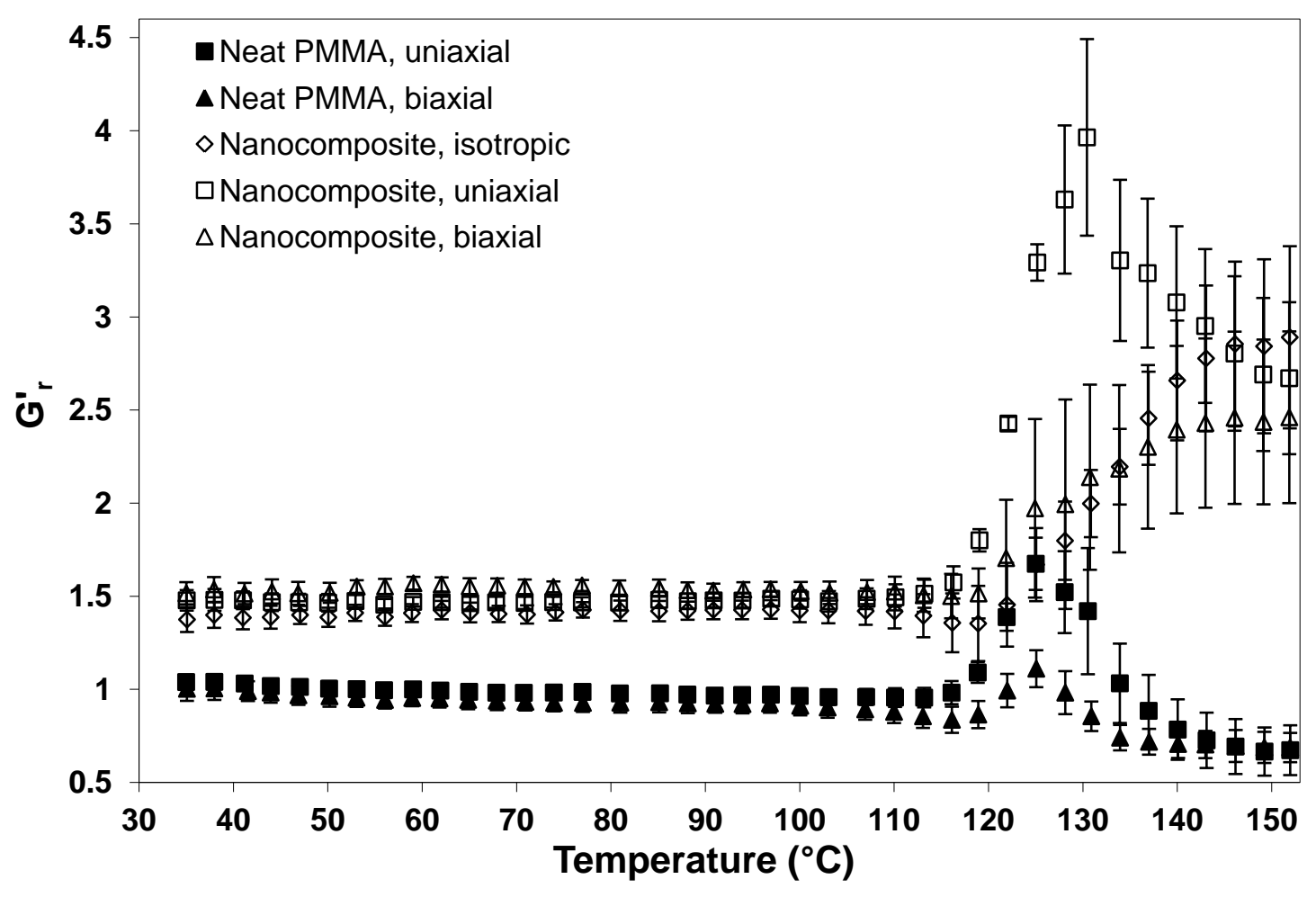

Figure 9. Relative storage modulus data for the PMMA-based samples. Data are normalized with respect to the storage modulus data for the isotropic neat PMMA sample.

The thermomechanical property trends were consistent with the structural data. The PEO neat samples and nanocomposite samples showed some property changes when subjected to different drawing steps, consistent with structural changes to the polymer matrix. The addition 
of nanoparticles enhanced these changes; however, distinctions between the nanoparticle arrangements (uniaxial and biaxial) could not be made at temperatures greater than $T_{g}$. This result indicated that connectivity between nanocomposite components was provided by amorphous polymer chains interacting with the nanoparticles. Given the relatively low aspect ratio of the nanoparticles used in this work, distinctions between the two nanoparticle arrangements (uniaxial and biaxial) were reduced when nanoparticle-polymer interactions were weakened. In a system with higher aspect ratio nanoparticles (resulting in a higher potential for load transfer), the microstructure-property relationships would be expected to be more evident. In research with carbon nanotube/high density polyethylene (HDPE) composites, clear distinctions in some mechanical properties were seen at temperatures greater than $T_{g}$ for samples subjected to uniaxial and sequential biaxial drawing, with the samples experiencing sequential biaxial drawing showing greater mechanical properties than the samples experiencing uniaxial drawing [65]. However in that composite system, the interactions between components were not expected to be large, and given the low $\mathrm{T}_{g}$ of HDPE, properties in the glassy regime could not be investigated, but these results in combination with the results contained in this paper suggest that with judicious materials selection greater property improvements could be realized with this design strategy.

However, the neat PEO samples did not show this same trend as the PEO-based nanocomposites. The neat sample subjected to two drawing steps showed similar values of $G^{\prime}$ at temperatures below $T_{g}$ and larger values of $G^{\prime}$ above $T_{g}$ with respect to the neat sample drawn uniaxially. This difference was attributed to the types of interactions present in the neat PEO samples and the nanocomposite samples. The neat PEO samples contained amorphous polymer chains and polymer crystallites. However, these components are not entirely distinct from one 
another. The polymer crystallites are connected to one another through amorphous polymer chains. These chains can be partially incorporated with one or more crystallites, exist at the crystallite surface, or exist in the interstitial space between polymer lamella. Depending on the crystal structure, the conformation of these amorphous chains can be constrained from their unperturbed state, and their conformations are further disturbed by the drawing processes, through affine extension of the polymer chains. Since the amorphous chains are constrained by the crystal structure, which is not changing as the testing temperature increases beyond $T_{g}$, the structure produced by the drawing was less affected by increasing temperature in the biaxial neat PEO sample than the biaxial PEO-based nanocomposite sample.

In contrast, the PEO-based nanocomposite samples have nanoparticle-polymer interactions as well as amorphous chain-crystallite interactions. The nanoparticle-polymer interactions are physical interactions and weakened by increasing temperature. Once these interactions were weakened, the nanoparticles were not as integrated into the tensioned matrix network, removing the benefits of the tensegrity-inspired structure. The trends observed in the comparison system with an amorphous matrix also indicated that the amorphous chain-crystallite interactions were an important aspect of producing the tensegrity-inspired structure. In a system with only nanoparticle-polymer interactions, matrix and nanoparticle structuring with sequential drawing steps was not as effective at producing distinct thermomechanical property improvements.

With regard to the efficacy of the tensegrity-inspired microstructure in producing mechanical reinforcement, the current study suggests that there could be benefits to employing this composite design. Considering the PEO-based nanocomposites, a higher degree of reinforcement was observed for the tensegrity-inspired design at temperatures less than $T_{g}$. Since 
the polymer matrix is essentially immobile and stiffer at these temperatures, it can be difficult to produce significant improvement with the addition of nanoparticles in this temperature regime without significant matrix structural change. One such example is increased matrix crystallinity through the nucleating effect of some nanoparticles. Often, more dramatic improvements are observed at temperatures greater than $T_{g}$, when the contrast in component properties (nanoparticles and matrix) is larger. The tensegrity-inspired approach did produce beneficial matrix structuring that appeared to promote better load transfer, performing better than a nanocomposite with a higher degree of nanoparticle alignment. Overall, the results obtained in this study suggested that a tensegrity-inspired composite design can produced through relatively simple processing to achieve improved mechanical properties.

\section{Conclusions}

The research described here was concerned with translating a design concept to a composite material microstructure. While the tensegrity structure has been used previously to describe the behavior of semicrystalline polymers and spider silk, its application to composite design has not been widely explored. Efforts to mimic the continuous tensioned phase and orient the compressed nanoparticle elements through sequential, perpendicular drawing steps was investigated and shown to improve stiffness. The approach was found to more effective with a semi-crystalline matrix than with an amorphous matrix, likely due to additional macromolecular constraints provided by amorphous chain-crystallite interactions. Additionally, studies to improve the results could focus on nanoparticles with larger aspect ratio to increase the contrast between component properties and study the effect of nanoparticle arrangement more clearly. Ultimately, this study provides new composite design options for discontinuously filled 
composites and contributes to the body of work concerning the complicated processingstructure-property relationships for polymer nanocomposites.

\section{Acknowledgements}

This material is based upon work supported by the National Science Foundation under

Grant No. CMMI-0800019. The authors also gratefully acknowledge funding from the Georgia Institute of Technology and the Solvay Advanced Polymers Young Faculty Award to MLS. 


\section{References}

[1] A.C. Balazs, T. Emrick, T.P. Russell, Nanoparticle polymer composites: Where two small worlds meet, Science 314 (2006) 1107-1110.

[2] L.L. Beecroft, C.K. Ober, Nanocomposite materials for optical applications, Chemistry of Materials 9 (1997) 1302-1317.

[3] E.P. Giannelis, Polymer layered silicate nanocomposites, Advanced Materials 8 (1996) 2935.

[4] E.P. Giannelis, R. Krishnamoorti, E. Manias, Polymer-silicate nanocomposites: Model systems for confined polymers and polymer brushes, Polymers in Confined Environments 138 (1999) 107-147.

[5] M. Moniruzzaman, K.I. Winey, Polymer nanocomposites containing carbon nanotubes, Macromolecules 39 (2006) 5194-5205.

[6] M. Samir, F. Alloin, A. Dufresne, Review of recent research into cellulosic whiskers, their properties and their application in nanocomposite field, Biomacromolecules 6 (2005) 612-626.

[7] E.T. Thostenson, Z.F. Ren, T.W. Chou, Advances in the science and technology of carbon nanotubes and their composites: A review, Composites Science and Technology 61 (2001) 18991912.

[8] C. Aulin, G. Salazar-Alvarez, T. Lindstrom, High strength, flexible and transparent nanofibrillated cellulose-nanoclay biohybrid films with tunable oxygen and water vapor permeability, Nanoscale 4 (2012) 6622-6628.

[9] S. Hotta, D.R. Paul, Nanocomposites formed from linear low density polyethylene and organoclays, Polymer 45 (2004) 7639-7654. 
[10] K. Kalaitzidou, H. Fukushima, L.T. Drzal, Multifunctional polypropylene composites produced by incorporation of exfoliated graphite nanoplatelets, Carbon 45 (2007) 1446-1452.

[11] P.B. Messersmith, E.P. Giannelis, Synthesis and barrier properties of poly(epsiloncaprolactone)-layered silicate nanocomposites, Journal of Polymer Science Part A-Polymer Chemistry 33 (1995) 1047-1057.

[12] E. Picard, A. Vermogen, J.F. Gerard, E. Espuche, Barrier properties of nylon 6montmorillonite nanocomposite membranes prepared by melt blending: Influence of the clay content and dispersion state - Consequences on modelling, Journal of Membrane Science 292 (2007) 133-144.

[13] M.A. Priolo, D. Gamboa, K.M. Holder, J.C. Grunlan, Super gas barrier of transparent polymer-clay multi layer ultrathin films, Nano Letters 10 (2010) 4970-4974.

[14] M.H. Al-Saleh, U. Sundararaj, Microstructure, electrical, and electromagnetic interference shielding properties of carbon nanotube/acrylonitrile-butadiene-styrene nanocomposites, Journal of Polymer Science Part B-Polymer Physics 50 (2012) 1356-1362.

[15] J.I. Lee, S.B. Yang, H.T. Jung, Carbon nanotubes-polypropylene nanocomposites for electrostatic discharge applications, Macromolecules 42 (2009) 8328-8334.

[16] K. Lozano, J. Bonilla-Rios, E.V. Barrera, A study on nanofiber-reinforced thermoplastic composites (II): Investigation of the mixing rheology and conduction properties, Journal of Applied Polymer Science 80 (2001) 1162-1172.

[17] S. Pande, A. Chaudhary, D. Patel, B.P. Singh, R.B. Mathur, Mechanical and electrical properties of multiwall carbon nanotube/polycarbonate composites for electrostatic discharge and electromagnetic interference shielding applications, RSC Advances 4 (2014) 13839-13849. 
[18] J.G. Smith, J.W. Connell, D.M. Delozier, P.T. Lillehei, K.A. Watson, Y. Lin, B. Zhou, Y.P. Sun, Space durable polymer/carbon nanotube films for electrostatic charge mitigation, Polymer 45 (2004) 825-836.

[19] X.Y. Huang, W.J. Brittain, Synthesis and characterization of PMMA nanocomposites by suspension and emulsion polymerization, Macromolecules 34 (2001) 3255-3260.

[20] T. Ramanathan, A.A. Abdala, S. Stankovich, D.A. Dikin, M. Herrera-Alonso, R.D. Piner, D.H. Adamson, H.C. Schniepp, X. Chen, R.S. Ruoff, S.T. Nguyen, I.A. Aksay, R.K. Prud'homme, L.C. Brinson, Functionalized graphene sheets for polymer nanocomposites, Nature Nanotechnology 3 (2008) 327-331.

[21] X.D. Cao, H. Dong, C.M. Li, New nanocomposite materials reinforced with flax cellulose nanocrystals in waterborne polyurethane, Biomacromolecules 8 (2007) 899-904.

[22] T.D. Fornes, P.J. Yoon, H. Keskkula, D.R. Paul, Nylon 6 nanocomposites: The effect of matrix molecular weight, Polymer 42 (2001) 9929-9940.

[23] J.J. Liang, Y. Huang, L. Zhang, Y. Wang, Y.F. Ma, T.Y. Guo, Y.S. Chen, Molecular-level dispersion of graphene into poly(vinyl alcohol) and effective reinforcement of their nanocomposites, Advanced Functional Materials 19 (2009) 2297-2302.

[24] T.X. Liu, I.Y. Phang, L. Shen, S.Y. Chow, W.D. Zhang, Morphology and mechanical properties of multiwalled carbon nanotubes reinforced nylon-6 composites, Macromolecules 37 (2004) 7214-7222.

[25] M.A. Rafiee, J. Rafiee, Z. Wang, H.H. Song, Z.Z. Yu, N. Koratkar, Enhanced mechanical properties of nanocomposites at low graphene content, ACS Nano 3 (2009) 3884-3890. 
[26] A.H. Pei, J.M. Malho, J. Ruokolainen, Q. Zhou, L.A. Berglund, Strong nanocomposite reinforcement effects in polyurethane elastomer with low volume fraction of cellulose nanocrystals, Macromolecules 44 (2011) 4422-4427.

[27] S. Kumar, T.D. Dang, F.E. Arnold, A.R. Bhattacharyya, B.G. Min, X.F. Zhang, R.A. Vaia, C. Park, W.W. Adams, R.H. Hauge, R.E. Smalley, S. Ramesh, P.A. Willis, Synthesis, structure, and properties of PBO/SWNT composites, Macromolecules 35 (2002) 9039-9043.

[28] F. Mai, K. Wang, M.J. Yao, H. Deng, F. Chen, Q.A. Fu, Superior reinforcement in meltspun polyethylene/multiwalled carbon nanotube fiber through formation of a shish-kebab structure, Journal of Physical Chemistry B 114 (2010) 10693-10702.

[29] M.L. Minus, H.G. Chae, S. Kumar, Interfacial crystallization in gel-spun poly(vinyl alcohol)/single-wall carbon nanotube composite fibers, Macromolecular Chemistry and Physics 210 (2009) 1799-1808.

[30] W.E. Teo, S. Ramakrishna, Electrospun nanofibers as a platform for multifunctional, hierarchically organized nanocomposite, Composites Science and Technology 69 (2009) 18041817.

[31] K.H. Yoon, M.B. Polk, B.G. Min, D.A. Schiraldi, Structure and property study of nylon6/clay nanocomposite fiber, Polymer International 53 (2004) 2072-2078.

[32] K. Young, F.M. Blighe, J.J. Vilatela, A.H. Windle, I.A. Kinloch, L.B. Deng, R.J. Young, J.N. Coleman, Strong dependence of mechanical properties on fiber diameter for polymernanotube composite fibers: Differentiating defect from orientation effects, ACS Nano 4 (2010) 6989-6997.

[33] E.D. Cranston, D.G. Gray, Morphological and optical characterization of polyelectrolyte multilayers incorporating nanocrystalline cellulose, Biomacromolecules 7 (2006) 2522-2530. 
[34] D.M. DeLongchamp, P.T. Hammond, High-contrast electrochromism and controllable dissolution of assembled Prussian blue/polymer nanocomposites, Advanced Functional Materials 14 (2004) 224-232.

[35] D.A. Hagen, L. Saucier, J.C. Grunlan, Controlling effective aspect ratio and packing of clay with $\mathrm{pH}$ for improved gas barrier in nanobrick wall thin films, ACS Applied Materials \& Interfaces 6 (2014) 22914-22919.

[36] Y.C. Li, J. Schulz, S. Mannen, C. Delhom, B. Condon, S. Chang, M. Zammarano, J.C. Grunlan, Flame retardant behavior of polyelectrolyte-clay thin film assemblies on cotton fabric, ACS Nano 4 (2010) 3325-3337.

[37] P. Podsiadlo, A.K. Kaushik, E.M. Arruda, A.M. Waas, B.S. Shim, J.D. Xu, H. Nandivada, B.G. Pumplin, J. Lahann, A. Ramamoorthy, N.A. Kotov, Ultrastrong and stiff layered polymer nanocomposites, Science 318 (2007) 80-83.

[38] S. Srivastava, N.A. Kotov, Composite layer-by-layer (LBL) assembly with inorganic nanoparticles and nanowires, Accounts of Chemical Research 41 (2008) 1831-1841.

[39] C.A. Grabowski, H. Koerner, J.S. Meth, A. Dang, C.M. Hui, K. Matyjaszewski, M.R. Bockstaller, M.F. Durstock, R.A. Vaia, Performance of dielectric nanocomposites: Matrix-free, hairy nanoparticle assemblies and amorphous polymer-nanoparticle blends, ACS Applied Materials \& Interfaces 6 (2014) 21500-21509.

[40] M.N. Tchoul, S.P. Fillery, H. Koerner, L.F. Drummy, F.T. Oyerokun, P.A. Mirau, M.F. Durstock, R.A. Vaia, Assemblies of titanium dioxide-polystyrene hybrid nanoparticles for dielectric applications, Chemistry of Materials 22 (2010) 1749-1759.

[41] R.B. Fuller, Tensegrity, Portfolio and Art News Annual 4 (1961) 112-127, 148. 
[42] R. Motro, Tensegrity: Structural Systems for the Future, Kogan Page Science, London, 2003.

[43] N. Wang, J.P. Butler, D.E. Ingber, Mechanotransduction across the cell-surface and through the cytoskeleton, Science 260 (1993) 1124-1127.

[44] N. Wang, K. Naruse, D. Stamenovic, J.J. Fredberg, S.M. Mijailovich, I.M. ToricNorrelykke, T. Polte, R. Mannix, D.E. Ingber, Mechanical behavior in living cells consistent with the tensegrity model, Proc. Natl. Acad. Sci. U. S. A. 98 (2001) 7765-7770.

[45] A.H. Simmons, C.A. Michal, L.W. Jelinski, Molecular orientation and two-component nature of the crystalline fraction of spider dragline silk, Science 271 (1996) 84-87.

[46] Y. Termonia, Molecular modeling of spider silk elasticity, Macromolecules 27 (1994) 73787381.

[47] T. Liedl, B. Hogberg, J. Tytell, D.E. Ingber, W.M. Shih, Self-assembly of three-dimensional prestressed tensegrity structures from DNA, Nature Nanotechnology 5 (2010) 520-524.

[48] D. Liu, M.S. Wang, Z.X. Deng, R. Walulu, C.D. Mao, Tensegrity: Construction of rigid DNA triangles with flexible four-arm DNA junctions, Journal of the American Chemical Society 126 (2004) 2324-2325.

[49] C. Sultan, R. Skelton, Deployment of tensegrity structures, International Journal of Solids and Structures 40 (2003) 4637-4657.

[50] A.G. Tibert, S. Pellegrino, Deployable tensegrity reflectors for small satellites, Journal of Spacecraft and Rockets 39 (2002) 701-709.

[51] W.T. Ren, A.C. Griffin, Mechanism of strain retention and shape memory in main chain liquid crystalline networks, Physica Status Solidi B-Basic Solid State Physics 249 (2012) 13791385. 
[52] A. Sidorenko, T. Krupenkin, A. Taylor, P. Fratzl, J. Aizenberg, Reversible switching of hydrogel-actuated nanostructures into complex micropatterns, Science 315 (2007) 487-490.

[53] F. Fraternali, G. Carpentieri, M. Modano, F. Fabbrocino, R.E. Skelton, A tensegrity approach to the optimal reinforcement of masonry domes and vaults through fiber-reinforced composite materials, Composite Structures 134 (2015) 247-254.

[54] D.W. Jensen, Using External Robots Instead of Internal Mandrels to Produce Composite Lattice Structures in: C. Binetruy, F. Boussu (Eds.), Recent Advances in Textile Composites2010, pp. 88-94.

[55] D.P. Williams, W.B. Carlson, W.A. Schulze, S.M. Pilgram, Composite hydrophone devices coupling piezoelectricity and tensegrity, Materials Research Innovations 3 (2000) 226-230.

[56] J.H. Lee, I.T. Kim, R. Tannenbaum, M.L. Shofner, Synthesis of polymer-decorated hydroxyapatite nanoparticles with a dispersed copolymer template, Journal of Materials Chemistry 22 (2012) 11556-11560.

[57] J.H. Lee, M.L. Shofner, Copolymer-mediated synthesis of hydroxyapatite nanoparticles in an organic solvent, Langmuir 29 (2013) 10940-10944.

[58] J.H. Lee, M.L. Shofner, Dispersion of polymer-decorated hydroxyapatite nanoparticles in poly(ethylene oxide) at low grafting densities, Polymer 53 (2012) 5146-5154.

[59] G. Vidotto, D. Levy, A.J. Kovacs, Crystallization and fusion of self-seeding polymers. I. Poly-1-butene polyethylene and polyoxyethylene of high molecular weight, Kolloid-Zeitschrift and Zeitschrift Fur Polymere 230 (1969) 289-305.

[60] Schubnell, M., "Measurement of Thin Films in Shear by DMA", Mettler Toledo Thermal Analysis User Com, 2009, 29. (available online at http://us.mt.com/us/en/home/supportive_content/matchar_apps/MatChar_UC293.html) 
[61] Samuels, R. J. "Structured Polymer Properties: The Identification, Interpretation, and Application of Crystalline Polymer Structure" John Wiley \& Sons, New York, 1974.

[62] X. Zhao, L. Ye, Structure and properties of highly oriented polyoxymethylene produced by hot stretching, Materials Science and Engineering: A 528 (2011) 4585-4591.

[63] A.K. Taraiya, M.S. Mirza, J. Mohanraj, D.C. Barton, I.M. Ward, Production and properties of highly oriented polyoxymethylene by die-drawing, Journal of Applied Polymer Science 88 (2003) 1268-1278.

[64] E. Guth, Theory of Filler Reinforcement, Journal of Applied Physics 16 (1945) 20-25.

[65] D. Xiang, E. Harkin-Jones, D. Linton, Characterization and structure-property relationship of melt-mixed high density polyethylene/multi-walled carbon nanotube composites under extensional deformation, RSC Advances 5 (2015) 47555-47568. 